\title{
Convective and Film Cooled Nozzle Extension for a High Pressure Rocket Subscale Combustion Chamber
}

\author{
D. I. Suslov*, R. Arnold ${ }^{\dagger}$ O. J. Haidn ${ }^{\ddagger}$ \\ German Aerospace Center (DLR), Institute of Space Propulsion, Lampoldshausen \\ 74239 Hardthausen, Germany
}

\begin{abstract}
Experimental investigations have been carried out to study heat transfer, flow separation, and side loads in a subscale nozzle extension. A Vulcain 2-like nozzle geometry has been tested with combustion chamber pressures up to $13 \mathrm{MPa}$. A new manufacturing technology has been demonstrated with minimized contour deformation during fabrication. Gaseous hydrogen was used to cool the upper part of the nozzle while flowing through helical, rectangular cooling channels. At a nozzle area expansion ratio of $\varepsilon=32$ the hydrogen has been injected with supersonic velocity as a film to protect the lower part of the nozzle from the influences of the hot gas. Investigations with varying coolant mass flow rates have shown a stable and safe nozzle operation at real rocket engine-like conditions.
\end{abstract}

\section{Nomenclature}
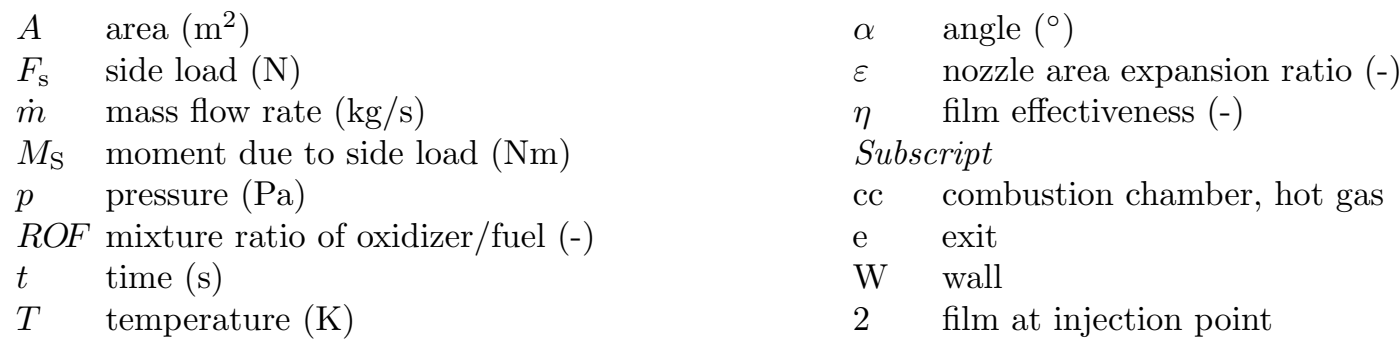

\section{Introduction}

$\mathrm{R}$ OCKET engine nozzles are designed to expand and accelerate the hot combustion gases to supersonic exit

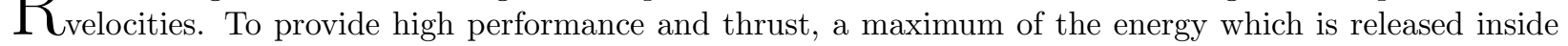
the combustion chamber due to the reaction of the propellant and the oxidizer has to be converted into kinetic energy. Especially rocket engines which are used for launch at sea-level as well within high-altitude conditions like the Space Shuttle Main Engine (SSME), the Vulcain 2 of the European launcher Ariane 5, or booster engines like the RD-170 family suffer from conceptual disadvantages since the operation at a non-optimum expansion area ratio reduces engine thrust and specific impulse. A nozzle with a non-flexible contour can only operate at ideal conditions when the pressure at the nozzle end equals the surrounding pressure. Since the atmospheric flight time is only a minor part of a rocket launch, first stage engine nozzles are optimized for lower surrounding pressures. However, to avoid flow separation at sea-level, which can destroy the nozzle structure, first stage engines operate at slightly over-expanded conditions at sea-level. Flow separation, atmospheric forces as well as weight and size restrictions limit the expansion ratio $\varepsilon$, which is defined by the comparison of nozzle exit area $A_{\text {exit }}$ and nozzle throat area $A_{\text {throat }}$ :

$$
\varepsilon=\frac{A_{\text {exit }}}{A_{\text {throat }}}
$$

*Corresponding Author; Research Engineer, AIAA Member, Email: dmitry.suslov@dlr.de

${ }^{\dagger}$ Currently Post Doctoral Scientist at Purdue University, West Lafayette, USA; AIAA Member, Email: arnold17@purdue.edu

${ }^{\ddagger}$ Head of Technology, Associate Fellow AIAA, Email: oskar.haidn@dlr.de 
Table1 summarizes typical nozzle expansion ratios as a function of application. ${ }^{1}$ Notable is the low expansion ratio of booster engines due to the comparable short duration time. Core stage engines with an operation time of up to 10 minutes feature a medium-range expansion ratio, whereas upper stage engines can reach extreme expansion ratios of more than 200.

Table 1. Nozzle expansion ratios

\begin{tabular}{lrr}
\hline \hline engine & $\varepsilon(-)$ & application \\
\hline F-1 & 16 & booster \\
RD-170, RD-180 & 36.9 & booster \\
Vulcain 2 & 57 & core \\
SSME & 69 & core \\
Vinci & 240 & upper stage \\
RL-10B & 250 & upper stage \\
\hline \hline
\end{tabular}

\section{A. Nozzle design and configurations}

Whereas the converging nozzle section or the throat contour design has only minor influence, the diverging supersonic-flow part is critical to thrust performance. Nozzle design parameters are high specific impulse, safe operation without flow separation, as well as low weight and small size. In the past, different nozzle configurations have been developed: ${ }^{2,3}$

- Conical nozzle. This is the oldest and simplest approach to convert thermal combustion energy into thrust. Despite a comparable low performance for a given length, conical nozzles are still applied for small low-thrust attitude control engines. The typical cone angle lies in the range of $30 \ldots 40^{\circ}$ to compromise good thrust behavior and reasonable nozzle length.

- Bell nozzle. Due to the axial flow of the hot gases at the end, this nozzle type results in a very high efficiency without divergence losses.

- Parabolic nozzle. Nozzles with a parabolic contour are bell nozzles with a shorter length and small divergence angles at the nozzle exit. Typical parabolic nozzles are truncated ideal contours (TIC), used for example in the Japanese LE-7 or the Russian RD-0120, and thrust-optimised contours (TOC), which are applied for example in the Vulcain 2, SSME, and RS-68.

- Advanced nozzles. To allow altitude compensation during launch, two-step contours like dual bell nozzles or extendible nozzles have been developed. Furthermore, plug nozzles or expansion-deflection nozzle concepts with aerodynamic boundaries instead of a solid outer nozzle structure have been tested successful. None of the advanced concepts is in a flight-ready development status. However, experimental studies have shown the potential of advanced nozzles for future high-performance propulsion concepts.

Materials for nozzles of upper stage engines have to show low weight due to the high expansion ratios and comparable large nozzle structures. Especially engines with very high expansion ratios like the Vinci engine or the RL-10B use $\mathrm{C} / \mathrm{C}$ materials for the nozzle extension. $\mathrm{C} / \mathrm{C}$ materials show high temperature resistance, which allows for reduced additional cooling efforts and results in a high engine performance.

Dump cooled nozzles for booster and core stage engines are mostly manufactured from nickel materials like inconel $\mathbb{R}$ alloys due to high temperature environments. To provide high stiffness and low weight, rectangular tubes are welded together to a helical structure. Dimensions of the cooling channels inside the tubes are in the range of a few millimeters.

\section{B. Cooling techniques}

High temperature differences between the hot combustion gases and the chamber walls yield to extreme high heat flux levels and temperature gradients through chamber and nozzle. In the past, a variety of different cooling techniques for rocket nozzles featuring short and long-time duration have been developed: ${ }^{2}$ 
- Ablative cooling is used especially for short-duration systems like booster engines with a limited operating time of about 2 minutes. Especially nozzles of solid rocket boosters use ablative cooling technique.

- Radiation cooling. With this method, comparatively low heat flux areas like nozzles of smaller lowperformance engines or nozzle parts of engines with higher heat loads are cooled.

- Dump cooling. With this principle, the coolant is pouring through cooling channels inside the liner material and is dumped overboard at the end of the nozzle skirt through sonic outlets (e.g. Vulcain), or is injected into the nozzle at a specific expansion ratio and used as a film for the downstream part of the nozzle section (e.g. Vulcain 2).

- Film cooling. This method can be used either alone for small nozzles with a low heat flux, or in combination with dump cooling at the lower nozzle section of engines with higher heat loads (e. g. Vulcain 2).

\section{Vulcain 2 nozzle design}

The Vulcain 2 is a typical example for a $\mathrm{LOX} / \mathrm{H}_{2}$ first stage gas generator engine. The vacuum thrust is $1350 \mathrm{kN}$ with an overall mass flow rate of $320 \mathrm{~kg} / \mathrm{s}$ and a specific vacuum impulse of $433 \mathrm{~s}$. Figure 1 (a) depicts the Vulcain 2 engine during a hot run on the P5 test bench at DLR Lampoldshausen.

The upper part of the nozzle structure features hydrogen dump cooling with a mass flow rate of approximately $3 \mathrm{~kg} / \mathrm{s}$, as shown in figure 1 (b). The coolant is flowing through helical rectangular arranged inconel $®$ tubes and convectively cools the structure while heating up. The geometry of the cooling channels features a width of $6 \mathrm{~mm}$ and a height of $4 \mathrm{~mm}$. The wall thickness of the tubes is $0.6 \mathrm{~mm}$. At a nozzle expansion ratio of $\varepsilon=32$ the hydrogen is dumped with supersonic velocity into the nozzle in the direction of the flow. Downstream the point of injection the hydrogen develops a coolant film which protects the lower nozzle section from heat impact of the accelerated combustion gases. Additional to the dumped hydrogen, the turbine exhaust gases (TEG) with a mass flow rate of approximately $10 \mathrm{~kg} / \mathrm{s}$ are injected as a film at almost the same position. To provide equal circumferential coolant distribution, the TEG is guided by two pipes from the upper part of the engine alongside the upper nozzle part to a manifold ring arranged before the coolant injection (see figure 1 (a)).

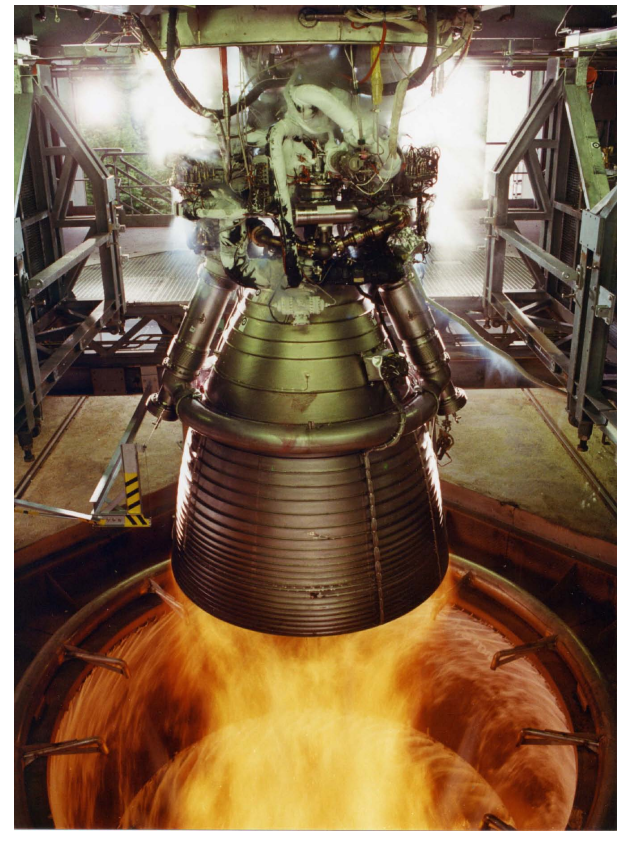

(a) Vulcain 2 engine at P5 test bench in Lampoldshausen ${ }^{4}$

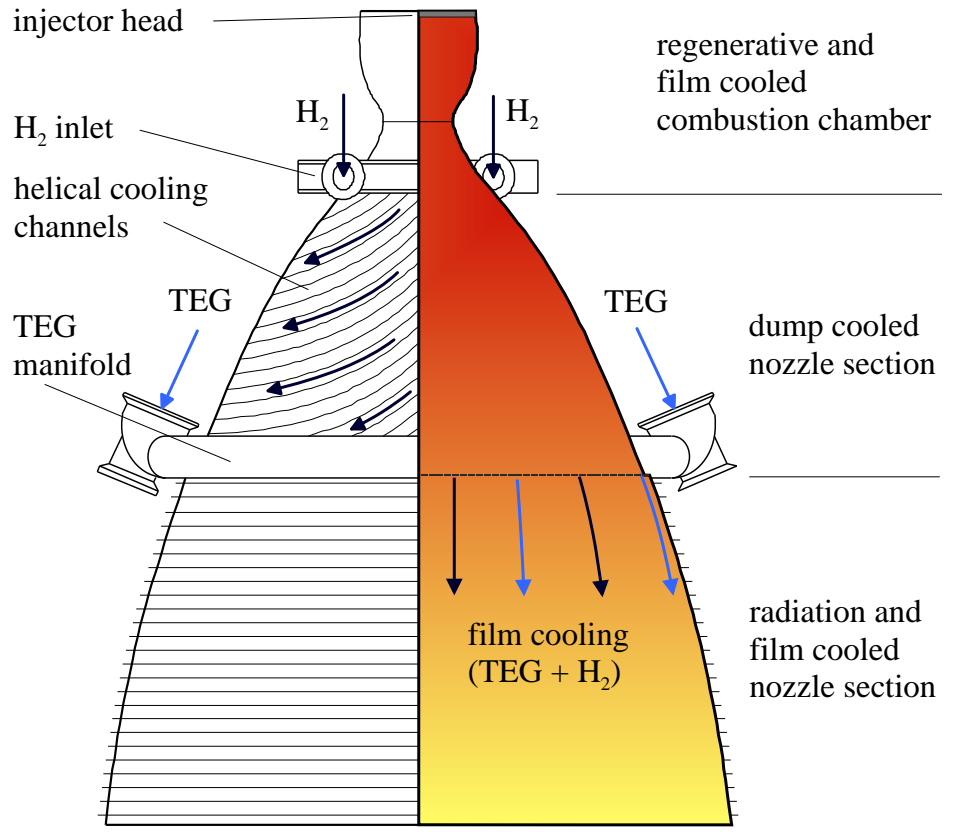

(b) Cooling design of combustion chamber and nozzle

Figure 1. Vulcain 2 engine 


\section{Experimental setup}

All investigations presented in this paper were performed at the European Research and Technology Test Facility P8 at DLR Lampoldshausen. This test facility permits investigations with liquid or gaseous hydrogen at typical rocket engine-like operating conditions. ${ }^{5}$

\section{A. Subscale combustion chamber}

DLR subscale combustion chamber "E" (BKE) was used to provide hot gas for the present nozzle investigations. BKE covers the full operating range of the European Vulcain 2 engine $\left(p_{\mathrm{cc}}=11.5 \mathrm{MPa} ; R O F=7.3\right)$ with an additional extension of this operating range. BKE has been successfully established in the past for a multiplicity of heat transfer and film cooling investigations. ${ }^{6-10}$ The combustion chamber features a cylindrical segment of $200 \mathrm{~mm}$ with a diameter of $50 \mathrm{~mm}$ and a nozzle throat segment with a throat diameter of $33 \mathrm{~mm}$. The cylindrical segment and the nozzle throat segment are cooled by water flowing through cooling channels (see figure 2).

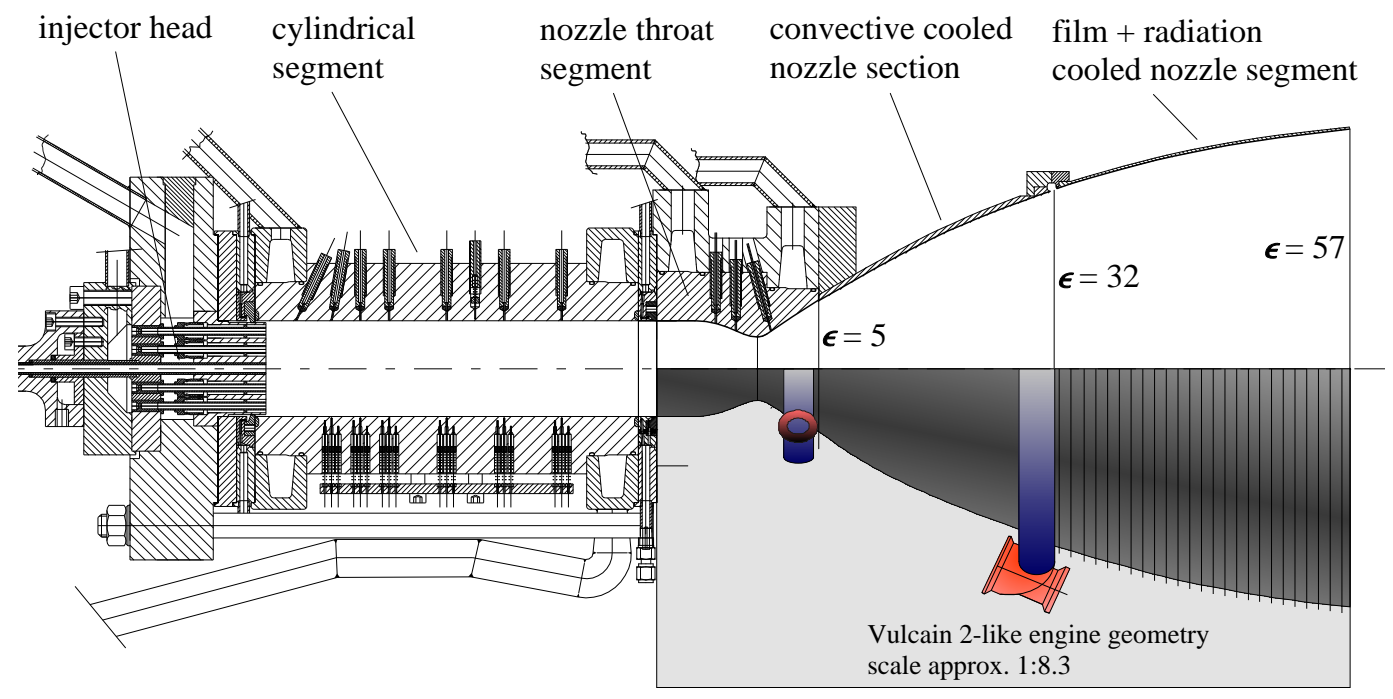

Figure 2. Subscale combustion chamber "E"

To investigate supersonic nozzle flow following the example of a Vulcain 2-like engine (see figure 1), a subscale nozzle extension has been developed. The nozzle extension was manufactured from the temperatureresistant nickel-chromium-based alloy inconel@ 600 , which also shows high mechanical strength. Together with the nozzle throat segment of BKE, a Vulcain 2-like engine geometry is represented with a reduction scale of approximately $1: 8.3$, as depicted also in figure 2. Like the Vulcain 2 nozzle, the subscale nozzle extension of chamber "E" consists of two sections: a convective cooled nozzle extension with helical cooling channels, which is attached to the nozzle throat segment at an expansion ratio of $\varepsilon=5$, and a film and radiation cooled nozzle skirt further downstream, starting at an expansion ratio $\varepsilon=32$.

On the contrary to the typical manufacturing technology for dump cooled nozzle sections, which includes complex and error-prone laser welding of rectangular tubes, a new method has been developed by DLR Lampoldshausen. The liner of the dump cooled nozzle section results from a metal spinning process of a thin inconel $\mathbb{R}$ sheet. After lathing the contour, helical cooling channels have been milled, resulting in a wall thickness between cooling channel bottom and hot gas side of only $0.5 \mathrm{~mm}$. The outer side of the cooling channels has been sealed with electroplating. This construction results in minimized material stress and contour deformation during manufacturing and allows high structural and thermal loads during hot run. The film and radiation cooled lower part of the nozzle extension also is the result of metal spinning and lathing. Before entering the nozzle, the heated hydrogen passes a flow straightener and a small convergentdivergent part to ensure supersonic conditions at the film injection point. Furthermore, an exchangeable ring at the film coolant outlet allows the simulation and investigation of different film injection velocities by featuring a constant mass flow ratio between hot gas and coolant. To ensure an equal circumferential coolant distribution, the ambient-tempered hydrogen is fed by four supply pipes. The film and radiation

$$
4 \text { of } 10
$$


cooled nozzle skirt is also changeable and enables the investigation of different nozzle geometries like a dual bell contour or materials like $\mathrm{C} / \mathrm{C}$.

Figure 3 (a) depicts the nozzle extension attached to subscale combustion chamber "E" at the test bench P8. The film injection at the nozzle expansion ratio $\varepsilon=32$ is clearly visible. The assembly and schematical flow separation due to the over-expansion at sea-level conditions is shown in figure 3 (b).

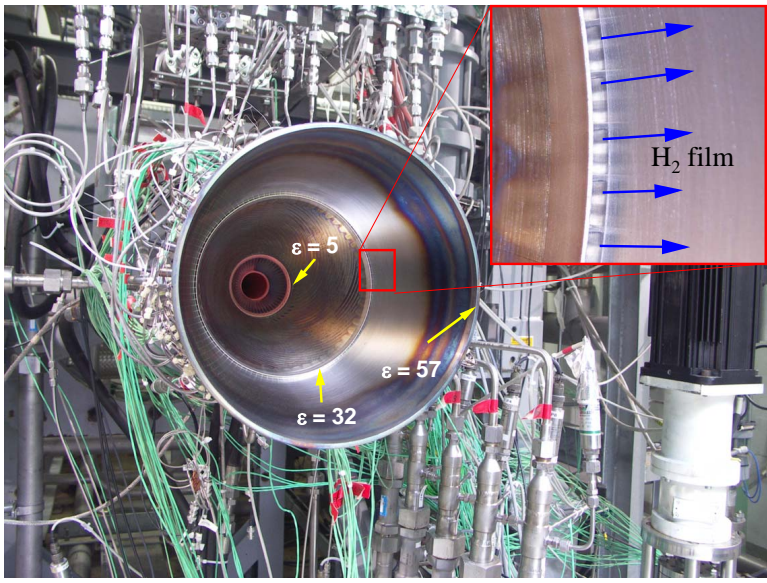

(a) BKE with nozzle extension at P8

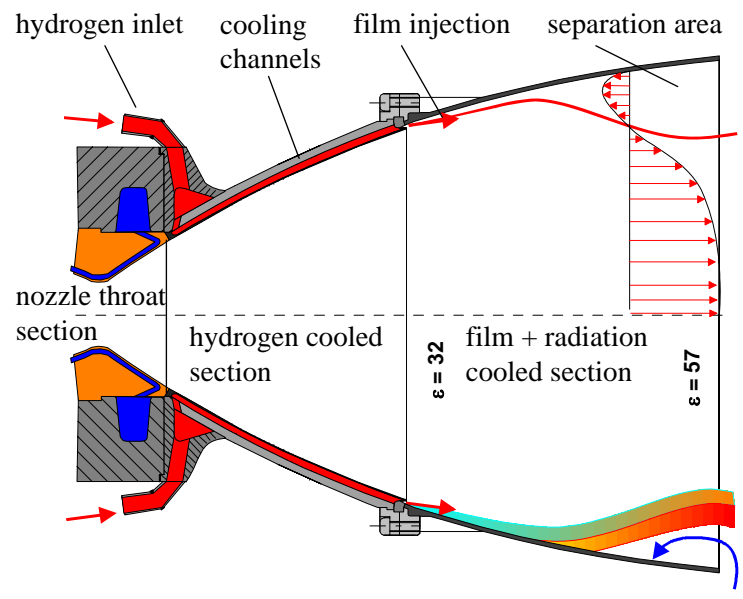

(b) Nozzle extension design and flow characteristic

Figure 3. BKE nozzle extension

\section{B. Measurement technique}

The nozzle extension of subscale chamber "E" is equipped with a variety of different sensors to study supersonic expansion flow characteristics with real engine-like hot gas conditions:

- Pressure transducers to measure the pressure drop inside the helical cooling channels as a function of coolant speed and flow distance, as well as the pressure distribution within the upper nozzle part and the nozzle skirt.

- Thermocouples arranged in packages of three to measure the temperature gradient inside the nozzle wall. Thermocouple packages are arranged between the cooling channels of the hydrogen cooled segment. Furthermore, wall thermocouples have been applied in the sheet of the film and radiation cooled nozzle skirt. A special DLR in-house method has been applied to ensure a stable positioning of the wall thermocouples during vibrations of hot run. The thermal gradient measured in the hydrogen cooled part allows the application of the gradient method to calculate the local heat flux density ${ }^{11-13}$

- Load cells to measure side loads due to combustion fluctuations, flow separation behavior, and nonuniform circumferential coolant distribution and film injection. Four load cells are located between the nozzle throat section and the hydrogen cooled lower part of the nozzle. An adjustable pre-load of the sensors ensures safe operation of the nozzle.

\section{Operating conditions}

A test sequence has been performed to model the start sequence of a typical hydrogen/oxygen operated engine at sea-level conditions. The combustion chamber pressure $p_{\mathrm{cc}}$ has been varied from $5 \mathrm{MPa}$ up to $11 \mathrm{MPa}$, applying a mixture ratio $R O F$ of 7.3 . After $25 \mathrm{~s}$ the mixture ratio has been reduced to $R O F=6.0$ while increasing the chamber pressure to $13 \mathrm{MPa}$. The last part of the sequence contains a pressure ramp down to $6 \mathrm{MPa}$ with a constant mixture ratio, as depicted in figure 4 (a). Figure 4 (b) shows subscale combustion chamber "E" with the attached nozzle extension (see figure 2) during a hot run at the test bench P8. The Mach disk which results from the over-expansion with a nozzle exit pressure $p_{\mathrm{e}}$ much smaller than the ambient pressure $p_{0}$ at sea-level condition is clearly visible. 


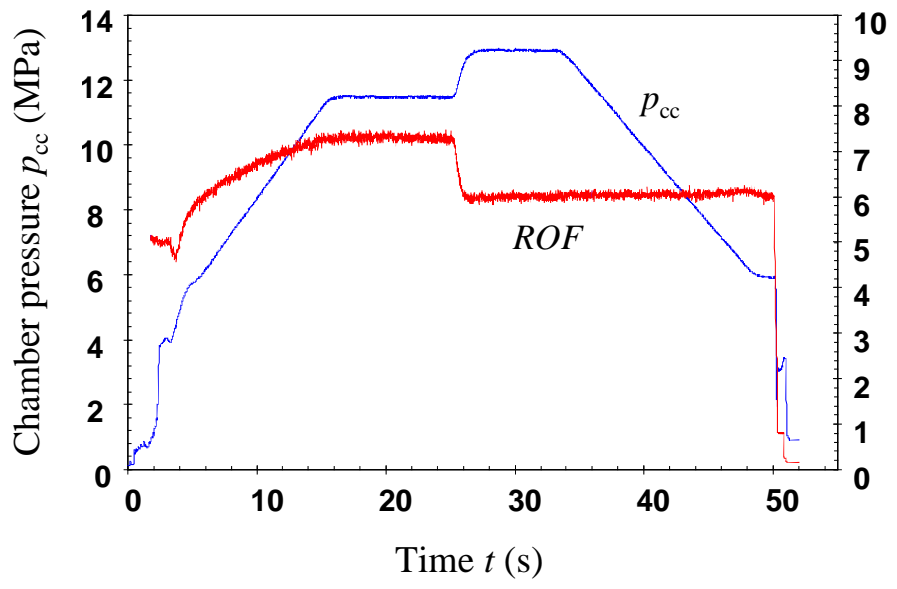

(a) Combustion chamber and mixture ratio

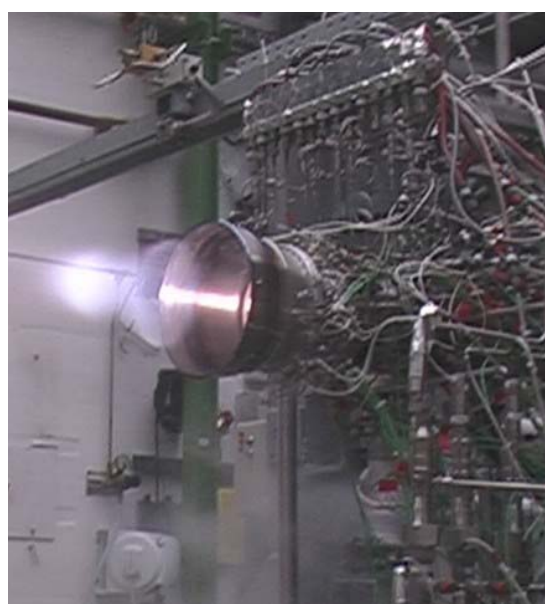

(b) BKE at P8 during hot run

Figure 4. Operating conditions and hot run

\section{Results and discussion}

The instrumentation of the nozzle extension allows detailed investigation of the behaviour of the flow in the separation area. Conventional measurement technique like pressure transducers and thermocouples has been combined with optical systems like infrared (IR) and the OH-intensity exposures.

The wall temperature of regions with high heat load exceeds $1200 \mathrm{~K}$, resulting in a cherry-red colored surface during hot run, as depicted in figure 5 (a). The highest temperatures of the structure occur downstream the film injection in the film and radiation cooled nozzle section. Temperatures in the hydrogen cooled part are significantly lower due to the effective hydrogen cooling. OH radicals which are light-emitting in the ultraviolet range show accurate determination of the location of heat release zones. Especially the partial burning of the injected hydrogen coolant at an expansion ratio of $\varepsilon=32$, which reacts with unburned oxygen from the injection at the injector head, is visible in the $\mathrm{OH}$ radical emission data, as shown in figure 5 (b). Especially for the design of ceramic $\mathrm{C} / \mathrm{C}$ nozzle structures, which itself react together with unburned oxygen molecules, the knowledge of the oxygen distribution and location is essential for a safe operation.

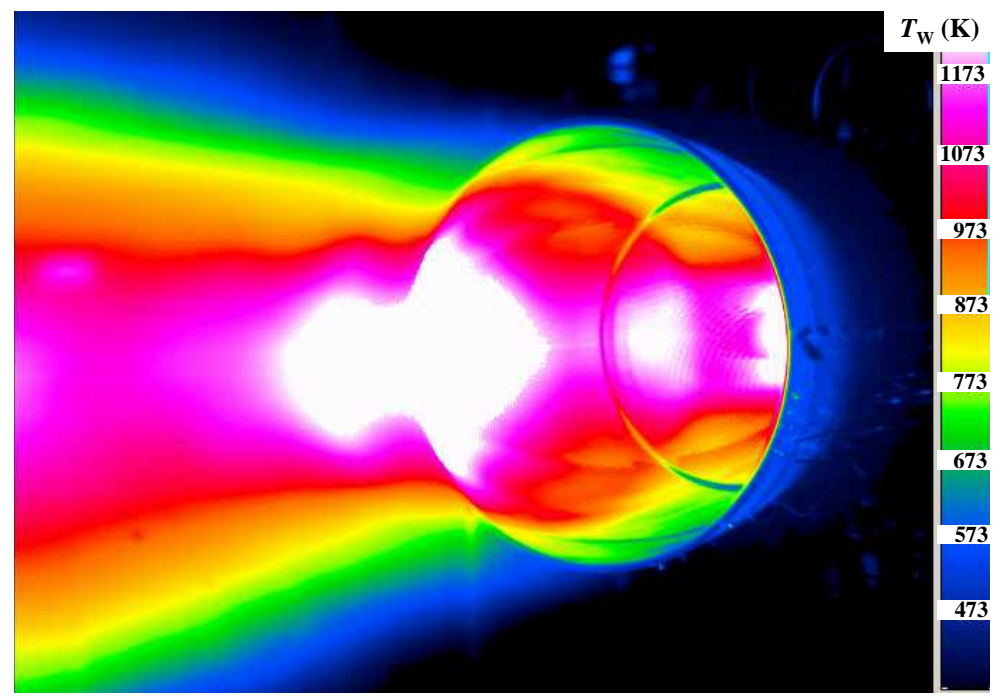

(a) Infrared photography

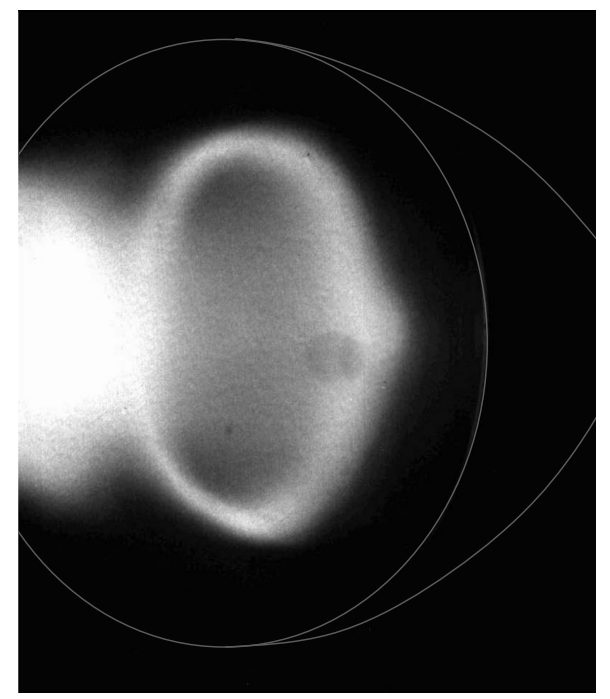

(b) $\mathrm{OH}$ intensity

Figure 5. Temperature distribution and $\mathrm{OH}$ intensity 
Figure 6 displays the nozzle exit pressure $p_{\mathrm{e}}$ as a function of the combustion chamber pressure $p_{\mathrm{cc}}$ (see figure $4(\mathrm{a}))$. For a chamber pressure of $p_{\mathrm{cc}}=11 \mathrm{MPa}$, the pressure at the nozzle exit has been measured as approximately $p_{\mathrm{e}}=0.032 \mathrm{MPa}$, and for a chamber pressure of $p_{\mathrm{cc}}=13 \mathrm{MPa}$ an exit pressure of $p_{\mathrm{e}}=$ $0.032 \mathrm{MPa}$ has been detected.

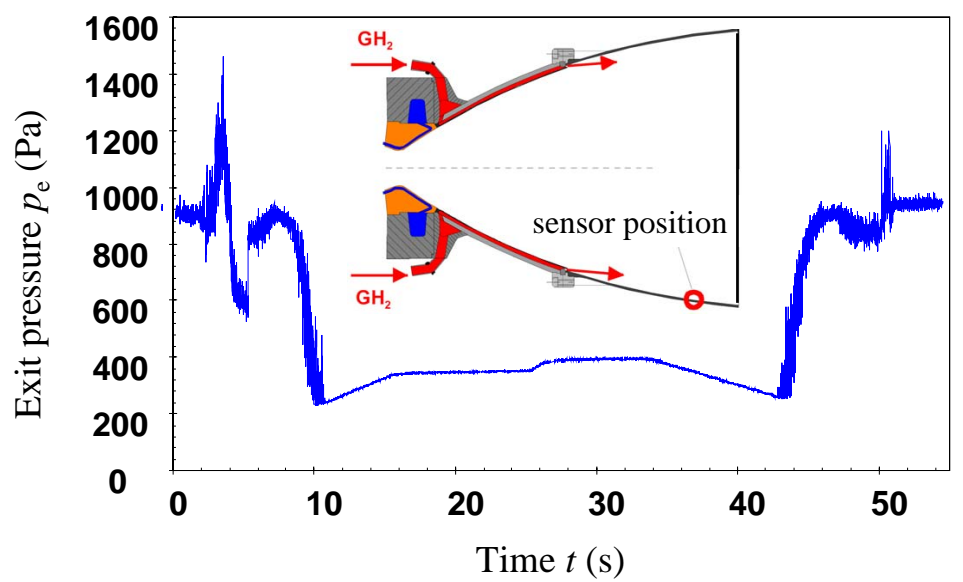

Figure 6. Nozzle exit pressure

As mentioned above, side loads have been measured by applying four load cells evenly in circumferential direction at the junction of the nozzle throat segment of BKE and the upper part of the nozzle extension. A small gap between the two segments allows the detection of side loads during hot run. Due to the full support of the nozzle extension on the four load cells not only the amount of the side load but also the angular position can be measured. The arrangement of the load cells as well as the angular position $\alpha$ of the side load can be seen in figure 7 (a). The location for $\alpha=0^{\circ}$ is at the position of load cell 1 .

Figure $7(\mathrm{~b})$ shows the resulting moment $M_{\mathrm{S}}$ due to the side load forces $F_{\mathrm{S}}$ as a function of the circumferential position $\alpha$. To calculate the resulting moment of the side loads, a center of rotation of the nozzle extension has been used. This center of rotation is given by the point of intersection of the tangents of the nozzle contour at the joint of the nozzle throat segment and the nozzle extension, as depicted in figure 7 (a). Side loads occur with a periodical pattern between the angular positions $\alpha \approx 30^{\circ}$ and $\alpha \approx 220^{\circ}$. Maximum side loads have been measured at the circumferential positions $\alpha \approx 30 \ldots 60^{\circ}$ and $\alpha \approx 150 \ldots 220^{\circ}$. The frequency of the measured resulting moment $M_{\mathrm{S}}$ is in the range of $1 / \Delta t=780 \mathrm{~Hz}$. The resulting side-load frequency at the angular positions with the maximum side load $\alpha \approx 30 \ldots 60^{\circ}$ and $\alpha \approx 150 \ldots 220^{\circ}$ is approximately $390 \mathrm{~Hz}$, respectively.

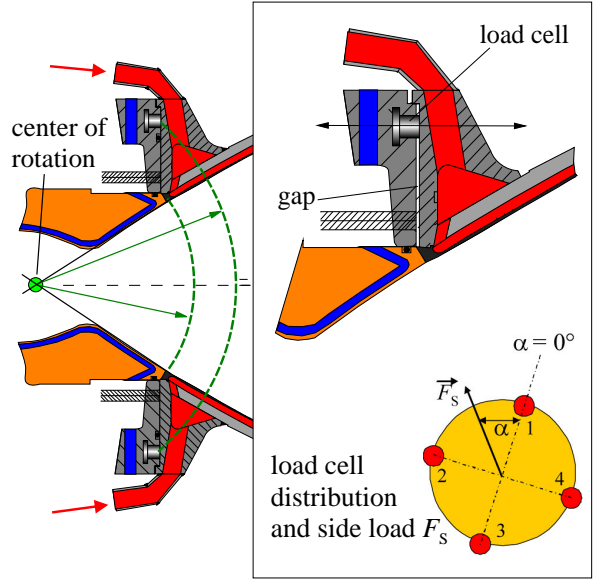

(a) Load cell arrangement

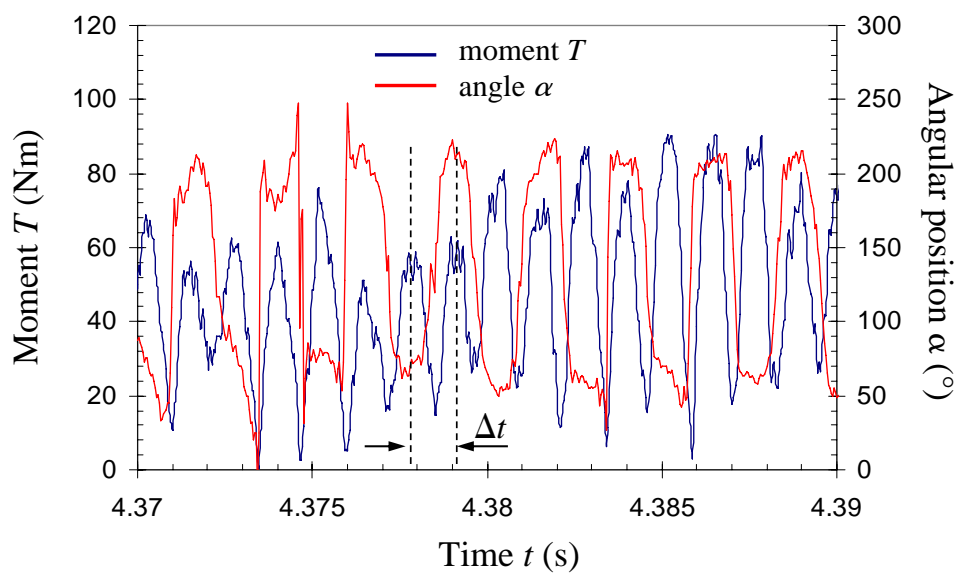

(b) Side load distribution

Figure 7. Side load measurement 
An important result is to point out that the side loads do not result in an oscillating revolving moment but in a moment that step-changes within $\pm 180^{\circ}$. The influence of friction due to the hydrogen feed lines and pressure transducers has been neglected for a first analysis due to the evenly distribution of the four hydrogen feed lines and the small tube dimensions.

One of the major goals of the present study was the influence of the film cooling injection on the flow separation behavior. For this purpose a special test sequence with two pressure ramps has been conducted. Within $10 \mathrm{~s}$ the chamber pressure has been raised from $6 \mathrm{MPa}$ to $11.5 \mathrm{MPa}$. After a stationary period of $10 \mathrm{~s}$ the combustion chamber pressure was reduced to the initial value of $6 \mathrm{MPa}$ within $10 \mathrm{~s}$. The test sequence in terms of combustion chamber pressure versus time is pictured in figure 8 (a). A constant hydrogen mass flow rate of $\left(\dot{m}_{\text {cool }} / \dot{m}_{\text {core }}\right)=4.5 \%$ has been used to dump-cool the upper part and film-cool the skirt of the nozzle extension. The axial positioning of the pressure transducers in the nozzle extension can be taken also from figure 8 (a).

The transition of the separation bubble within the nozzle extension at different axial positions can be seen in figure $8(\mathrm{~b})$. The transition period is in the range of $1.5 \ldots 2 \mathrm{~s}$ and is characterized due to pressure oscillations of approximately $\pm 0.02 \mathrm{MPa}$. After the transition of the separation bubble the pressure variations disappear almost completely, when the combustion chamber pressure reaches approximately 8.5 MPa. The comparable high pressure oscillations at the axial position 1 result from the close film coolant injection, as can be seen in figure $8(\mathrm{a})$.

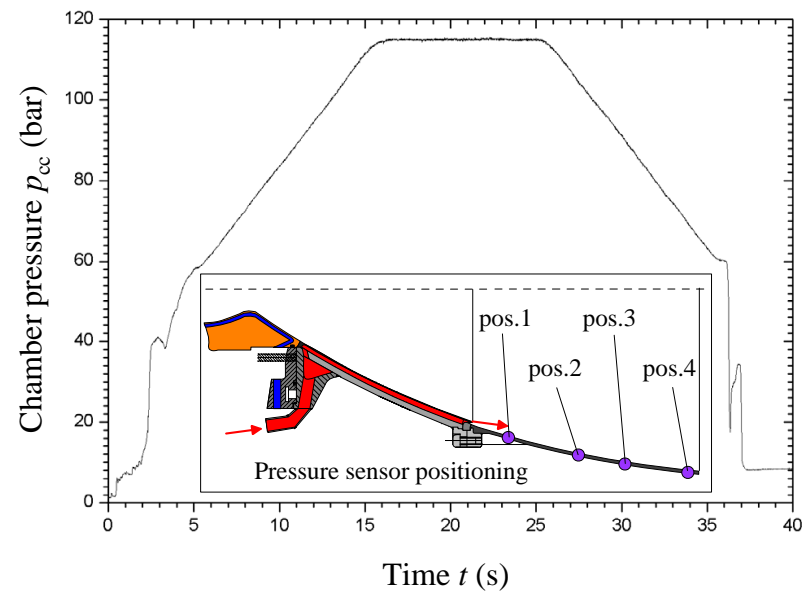

(a) Combustion chamber pressure and pressure sensor arrangement in the nozzle segment

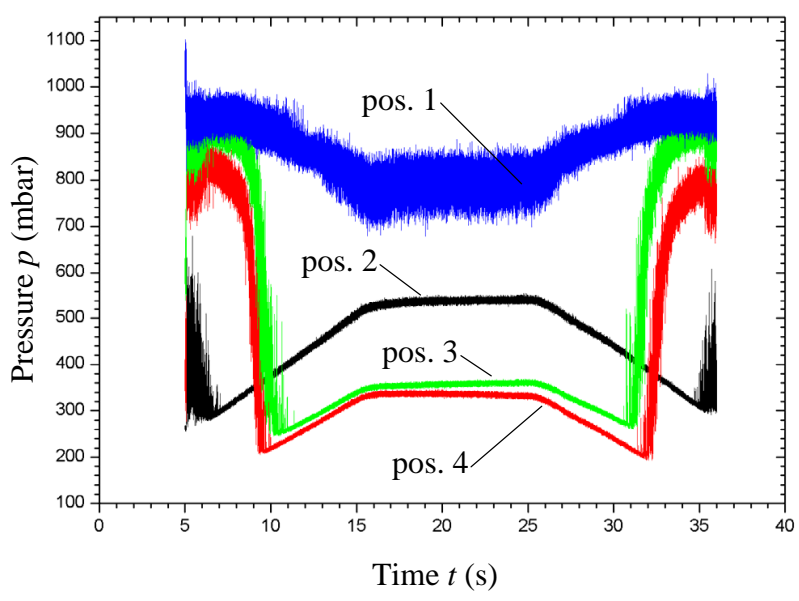

(b) Pressure in the nozzle skirt

Figure 8. Separation behavior investigation

To investigate the film cooling effectiveness $\eta$ downstream the point of injection at a nozzle expansion ratio $\varepsilon=32$ (see figure2(b)), the following definition has been used within the present study: ${ }^{14-16}$

$$
\eta=\frac{T_{\mathrm{W}}-T_{\mathrm{cc}}}{T_{2}-T_{\mathrm{cc}}}
$$

$T_{\mathrm{W}}$ indicates the measured local wall temperature in the nozzle skirt, and $T_{2}$ is the film injection temperature. $T_{\mathrm{cc}}$ describes a calculated total hot gas temperature in the combustion chamber, and is a reference temperature for the film cooling investigations in the nozzle skirt.

Figure 9 (a) depicts the film effectiveness $\eta$ in the nozzle skirt as a function of the axial distance downstream the point of injection. The film coolant mass flow rate has been varied in the range of $\left(\dot{m}_{\text {cool }} / \dot{m}_{\text {core }}\right)=3.4 \ldots 4.1 \%$. A higher film mass flow rate results in a lower local wall temperature and increased film effectiveness. Naturally, the effectiveness equals 1 at the point of injection with the assumption of $T_{\mathrm{W}}=T_{2}$. Further downstream, a mixing of the hot combustion gases and the injected hydrogen film occurs, and the local film effectiveness is reduced. However, $150 \mathrm{~mm}$ downstream the film injection the effectiveness $\eta$ is still in the range of $90 \%$.

The influence of the mixture ratio $R O F$ on the film effectiveness can be seen in figure 9 (b) for the position in close proximity of the nozzle exit (sensor pos. 4 , see figure $8(\mathrm{a})$ ) as a function of the film mass 
flow rate $\left(\dot{m}_{\text {cool }} / \dot{m}_{\text {core }}\right)$. An increased mixture ratio gives a slightly higher film cooling effectiveness within the investigated range of film mass flow rates.

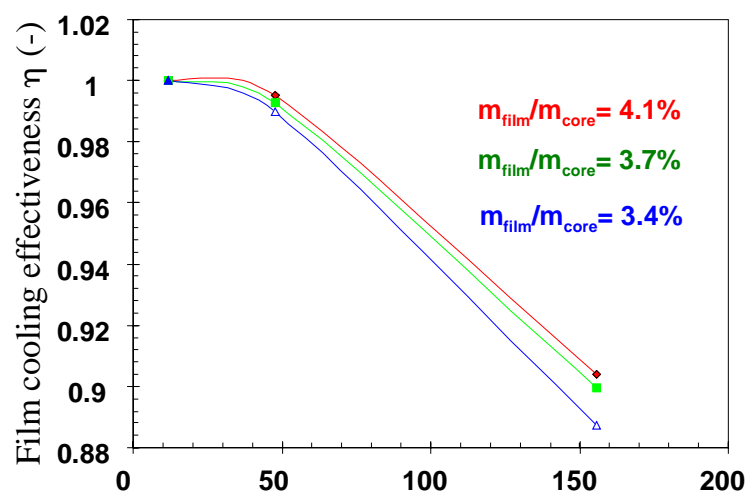

Distance downstream film injection $(\mathrm{mm})$

(a) Film cooling effectiveness

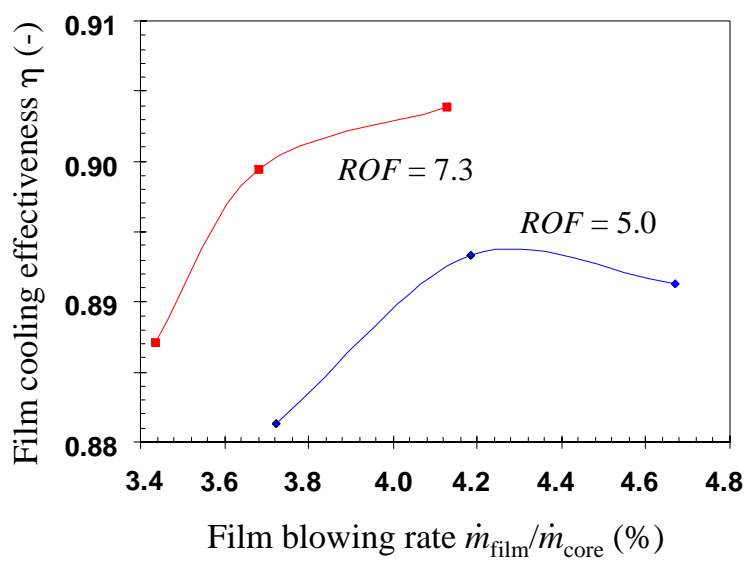

(b) Influence of $R O F$ at sensor pos. 4

Figure 9. Film cooling

\section{Conclusions}

First investigations with a newly developed nozzle extension have shown a successful and satisfying behavior during hot run with combustion chamber pressures up to $13 \mathrm{MPa}$ at high oxidizer/fuel mixture ratios. Temperature and pressure data confirmed the ideal design of the nozzle structure which was the result of a newly developed manufacturing process for convective cooled nozzles with integrated helical cooling channels. A variety of measurement technique allowed the investigation of the flow separation of this Vulcain 2-like over-expanded nozzle. As a novelty, the application of load cells at the joint of the already existing throat segment and the newly developed nozzle extension resulted in a detailed measurement of the circumferential distribution of nozzle side loads. The investigation of film cooling showed the effectiveness of the injected hydrogen film to protect the lower part of the nozzle extension.

Further investigations at DLR Lampolshausen regarding heat transfer and film cooling of the nozzle extension are planned in the near future.

\section{Acknowledgement}

The tireless support of A. Rohatschek during the construction and manufacturing process of the nozzle extension is greatly acknowledged by the authors. The authors would also like to acknowledge the P8 team for their assistance at the test campaign.

\section{References}

${ }^{1}$ Sutton, G. P., "History of Liquid Propellant Rocket Engines in the United States," Journal of Propulsion and Power, Vol. 19, No. 6, 2003, pp. 978-1007.

${ }^{2}$ Huzel, D. K. and Huang, D. H., Modern Engineering for Design of Liquid-Propellant Rocket Engines, Vol. 147 of Progress in Astronautics and Aeronautics, American Institute of Aeronautics and Astronautics (AIAA), Rocketdyne Division of Rockwell International, ISBN 1-56347-013-6, 1992.

${ }^{3}$ Hagemann, G. and Frey, M., "Shock Pattern in the Plume of Rocket Nozzles: Needs for Design Consideration," Shock Waves, Vol. 17, 2008, pp. 387-395.

${ }^{4}$ Deutsches Zentrum für Luft- und Raumfahrt e. V. (DLR), Institut für Raumfahrtantriebe (German Aerospace Center, Institute of Space Propulsion), http://www.dlr.de/ra/, Lampoldshausen, 74239 Hardthausen, Germany, December 2007.

${ }^{5}$ Koschel, W. W., Haidn, O. J., and Krülle, G., "P8 - The New French/German Test Facility for $\mathrm{H}_{2} / \mathrm{O}_{2}$-High Pressure Rocket Engine Combustion Research," Int. J. Hydrogen Energy, Vol. 23, No. 8, 1998, pp. 1815-1825.

${ }^{6}$ Suslov, D., Arnold, R., and Haidn, O. J., "Investigation of Two Dimensional Thermal Loads in the Region Near the Injector Head of a High Pressure Subscale Combustion Chamber," 47th AIAA Aerospace Sciences Meeting, Orlando, FL, January 4th-8th 2009, AIAA-2009-0450. 
${ }^{7}$ Arnold, R., Experimentelle Untersuchungen zur Filmkühlung in Raketenbrennkammern, Ph.D. thesis, Universität Stuttgart, December 2008.

${ }^{8}$ Arnold, R., Suslov, D., and Haidn, O. J., "Circumferential Film Cooling Effectiveness in a LOX/H 2 Subscale Combustion Chamber," Journal of Propulsion and Power, Vol. 25, No. 3, May-June 2009, pp. 760-770.

${ }^{9}$ Arnold, R., Suslov, D., and Haidn, O. J., "Film Cooling of Accelerated Flow in a Subscale Combustion Chamber," Journal of Propulsion and Power, Vol. 25, No. 2, March-April 2009, pp. 443-451.

${ }^{10}$ Arnold, R., Suslov, D., Oschwald, M., Haidn, O. J., Aichner, M., Ivancic, B., and Frey, M., "Experimentally and Numerically Investigated Film Cooling in a Subscale Rocket Combustion Chamber," 3rd European Conference for AeroSpace Sciences (EUCASS), Versailles, France, 6th-9th July 2009, EUCASS2009-51.

${ }^{11}$ Suslov, D., Woschnak, A., Sender, J., Oschwald, M., and Haidn, O., "Investigation of Heat Transfer Processes in Cooling Channels of Rocket Engines at Representative Operating Conditions," Space Challenge in 21st Century. 100 Years after the Tsiolkovskiy Idea on Space Missions Using Reactive Motors, Moscow - Kaluga, September 15th-19th 2003.

${ }^{12}$ Suslov, D., Woschnak, A., Greuel, D., and Oschwald, M., "Measurement Techniques for Investigation of Heat Transfer Processes at European Research and Technology Test Facility P8," European Conference for Aerospace Sciences (EUCASS), Moscow, July 4th-7th 2005.

${ }^{13}$ Arnold, R., Suslov, D., and Haidn, O. J., "Influence Parameters on Film Cooling Effectiveness in a High Pressure Subscale Combustion Chamber," 47th AIAA Aerospace Sciences Meeting, Orlando, FL, January 4th-8th 2009, AIAA-2009-0453.

${ }^{14}$ Eckert, E. R. G. and Birkebak, R. C., "The Effects of Slot Geometry on Film Cooling," Heat Transfer, Thermodynamics, and Education. McGraw-Hill Book Co., Inc., edited by H. A. Johnson, 1964, pp. 150-163.

${ }^{15}$ Goldstein, R. J. and Haji-Sheikh, A., "Prediction of Film Cooling Effectiveness," JSME 1967 Semi-International Symposium, Tokyo, Japan, September 4th-8th 1967, Paper No. 225.

${ }^{16}$ Goldstein, R. J., "Film Cooling," Advances in Heat Transfer, Vol. 7, 1971, pp. 321-379. 